\title{
"Retrato da Abstinência": distanciamentos da integralidade do cuidado no corpo- abstinente das pessoas que usam drogas, vivem em situação de rua e com HIV/Aids
}

"Portrait of Abstinence": distances from integrality of care in the abstinent body of people who use drugs, live on the street and with HIV/Aids

"Retrato de la Abstinencia": distancias de la integralidad del cuidado en el cuerpo abstinente de personas que usan drogas, viven en la cally y com VIH/SIDA

\section{Resumo}

O objeto deste estudo é, portanto, compreender o cuidado ao corpo-abstinente das pessoas que fazem uso de drogas, estão em situação de rua e vivem com HIV/Aids. Trata-se de um estudo de natureza qualitativa realizado no município de Fortaleza, capital do estado do Ceará. Ele foi fundamentado na hermenêutica fenomenológica de Paul Ricouer. Partirmos da perspectiva das narrativas e, assim, foi possível nos debruçarmos nas entrelinhas de falas e expressões dos participantes do estudo. De modo geral, através das narrativas dos trabalhadores de saúde, foi possível perceber o que o corpo de um usuário de drogas, que vive com HIV/Aids e em situação de rua significa e representa ao serviço de atenção à saúde. À guisa-se de conclusão, as subjetividades de um corpo-abstinente que vive com HIV/Aids, em situação de rua e que faz uso abusivo de drogas é enxergado dentro do sistema de saúde como problemático, agressivo, caprichoso e que não quer tratamento.

Palavras-chave: Síndrome da Imunodeficiência Adquirida; Pessoas em situação de rua; Drogas; Corpo; Abstinência.

\begin{abstract}
The object of this study is, therefore, to understand the care of the abstinent body of people who use drugs, are homeless and live with HIV/AIDS. This is a qualitative study carried out in the city of Fortaleza, capital of the state of Ceará. It was grounded in Paul Ricouer's phenomenological hermeneutics. We started from the perspective of the narratives and, thus, it was possible to look between the lines of speeches and expressions of the study participants. In general, through the health workers' narratives, it was possible to perceive what the body of a drug user, who lives with HIV/AIDS and who lives on the streets, means and represents to the health care service. By way of conclusion, the subjectivities of an abstinent-body who lives with HIV/Aids, in a street situation and who abuses drugs is seen within the health system as problematic, aggressive, capricious and who does not want treatment.
\end{abstract}

Keywords: Acquired Immunodeficiency Syndrome; Street people; Drugs; Body; Abstinence. 


\begin{abstract}
Resumen
El objeto de este estudio es, por lo tanto, comprender el cuidado del cuerpo abstinente de personas que usan drogas, están en situación de calle y viven con VIH/SIDA. Se trata de un estudio cualitativo realizado en la ciudad de Fortaleza, capital del estado de Ceará. Se basó en la hermenéutica fenomenológica de Paul Ricouer. Desde la perspectiva de las narrativas, fue posible mirar entre líneas y expresiones de los participantes del estudio. En general, a través de las narrativas de los trabajadores de la salud, fue posible percibir lo que el cuerpo de un usuario de drogas, que vive con VIH/SIDA y que vive en la calle, significa y representa para el servicio de salud. A modo de conclusión, las subjetividades de un cuerpo abstinente que vive con VIH/Sida, en situación de calle y que abusa de las drogas es visto dentro del sistema de salud como problemático, agresivo, caprichoso y que no quiere tratamiento.

Palabras clave: Síndrome de Inmunodeficiencia Adquirida; Gente en la calle; Drogas; Cuerpo; Abstinencia.
\end{abstract}

\title{
1. Introduçãa
}

Para Schwengber (2005), Ivo (2012) e Resende et al. (2017) devemos interpretar o corpo do sujeito como uma unidade corpórea singular no mundo, como uma complexidade representada pelo entrelaçamento do pensar, sentir, expressar e agir de cada um, formando assim, um sujeito singular e integral. Entender a história que este corpo percorreu é necessário para entendermos a integralidade do sujeito, partindo do pressuposto que um corpo é a casa de um ser humano, com memórias, emoções, cicatrizes, marcas e histórias. Ele de fato representa o que é vivido.

Segundo Le Breton (2011), o corpo, como a fisionomia do sujeito, é construído e expressado na sociedade por meio de suas histórias, sendo vetor semântico construído por variáveis como: atividades perspectivas, mas, sobretudo, expressão de sentimentos, conjunto de gestos e memórias. Isso resulta na produção da aparência expressada também por técnicas do corpo, exercícios físicos, relação com a dor, com o sofrimento, bem como expressa desejos sexuais. O autor ainda traz que, antes de qualquer coisa, a existência é corporal.

Diante disso, a relação do viver com HIV/Aids, em situação de rua, o uso abusivo da droga e como dar-se-á as suas representações no serviço em saúde e sociedade. Epele (2012) e Góis (2017) referem que há uma baixa adesão ao tratamento; o uso de múltiplas drogas e a repercussão na sua condição de saúde e como o fator principal das internações, a "alta a pedido", fragilidade/rompimento dos vínculos familiares e sociais, o medo da discriminação e do preconceito tanto pelo viver com HIV, como pelo uso de crack e a falta de suporte afetivo/social/material para lidar com a complexidade do regime terapêutico são elementos que dificultam mais ainda a adesão ao cuidado em saúde (Pedrosa et al., 2016; Castel , 2010).

Para tanto, quando entendemos o que é o corpo com HIV/Aids, que faz uso de drogas e que vive em situação de rua segundo a sociologia - conseguimos interpretar o que ele representa segundo as suas decisões, razões, necessidades e (re)construções, pois conseguimos rastrear e compreender seu local de fala, partindo, claro, de uma subjetividade do sujeito. Assim, é necessário reconhecer a importância da ampliação do olhar e da escuta dos trabalhadores para que a complexidade de vida e o sofrimento das pessoas possam ser consideradas nas práticas de saúde, como trazem Merhy e Feuerwerker (2009).

Para isto, com o intuito de problematizar a pertinência dessa questão, com ênfase em um sujeito que se encontra em abstinência, pelo tratamento que lhe é imposto em um centro de referência de doenças infectocontagiosas, encontra-se em conformidade, entender como o cuidado é perpassado com essas realidades, partindo da premissa, a subjetividade do indivíduo.

Machado et al. (2020) trazem ainda, em suas discussões, que poucos estudos foram realizados para compreender o que as pessoas que usam drogas demandam, necessitam ou esperam dos serviços de atenção. Logo, a contribuição que este estudo pode trazer encontra-se na possibilidade de reorientações de saberes e práticas dos profissionais de saúde para com os usuários do serviço, entendendo a singularidade deste corpo em abstinência, que está em situação de rua e que vive com HIV/Aids. 
Diante das considerações até aqui apresentadas, surgiram-se como perguntas norteadoras: como o corpo-abstinente das pessoas que usam drogas, estão em situação de rua e vivem com HIV/Aids são vistos na atenção em saúde? Como isso implica na formação do corpo-abstinente? Como é construído o cuidado ao corpo-abstinente?

O objetivo deste estudo é, portanto, compreender o cuidado ao corpo-abstinente das pessoas que fazem uso de drogas, estão em situação de rua e vivem com HIV/Aids. Seu objeto de análise recai sobre a representação que os trabalhadores de saúde possuem sobre esse corpo-abstinente e como isso implica na objetivação e subjetivação e no cuidado em saúde.

\section{Metodologia}

Trata-se de um estudo de natureza qualitativa realizado no município de Fortaleza, capital do estado do Ceará. Ele foi fundamentado na hermenêutica fenomenológica de Paul Ricouer (1989). Por ser um estudo cujo objeto não pode ser quantificado, por se referir a um nível de realidade que não pode ser mensurado (Minayo, 2013), partirmos da perspectiva das narrativas que, assim, foi possível nos debruçarmos nas entrelinhas de falas e expressões dos participantes do estudo.

A pesquisa ocorreu num serviço de atenção terciária para doenças infectocontagiosas, entre elas, o HIV/Aids. A coleta de dados foi de janeiro a março de 2020. Conquanto, participaram da pesquisa trabalhadores de saúde que atuam há mais de um ano no serviço e prestam ou prestaram assistência direta a sujeitos usuários de drogas em situação e de rua e que vivem com HIV/Aids. Foram excluídos aqueles que estavam de licença ou ausentes no serviço no momento da coleta. Assim, a partir dos critérios de inclusão e exclusão, oito interlocutores participaram do estudo.

A coleta de dados deu-se por meio da entrevista em profundidade guiada por conteúdos que abrangeram aspectos político-normativos dos serviços e ações de cuidados aos usuários com HIV/Aids, que fazem uso de drogas e que vivem em situação de rua. Vale ainda ressaltar que as entrevistas foram gravadas num dispositivo smartphone e armazenadas na íntegra em arquivos digitais privativos, garantindo anonimato e segurança para com os participantes do estudo. Foram, por sua vez, transcritas para serem analisadas e reanalisadas. Como forma de garantir o anonimato, utilizamos nomes de flores raras para identificar os trechos das falas dos interlocutores.

A análise das narrativas foi baseada na hermenêutica fenomenológica de Paul Ricouer (1989) que vislumbre um método reflexivo capaz de romper toda e qualquer ligação com a idealidade; o que se tornou imprescindível no presente estudo. Para tanto, percorremos cinco temas que são passos metodológicos que Ricouer (1989) propõe para a objetivação os quais possibilitaram o distanciamento e a apropriação, que juntamente com a explicação e a compreensão permearam a interpretação: a efetuação da linguagem como discurso, do discurso como obra estruturada; a relação da fala com a escrita no discurso e nas obras do discurso; a obra do discurso como projeção de um mundo; o discurso e a obra de discurso como mediadores da compreensão de si.

Conquanto, o processo da interpretação dos dados se deu através das seguintes fases: transcrição das entrevistas em texto, interpretação superficial, análise estrutural e compreensão abrangente do texto (Caprara \& Veras, 2005). Esse processo interativo é representado em forma de espiral, pois relaciona as partes do texto como o todo e vice-versa. Assim, surgiu a temática central. Após a transcrição na íntegra das entrevistas, a leitura e releitura de falas e expressões, fora realizado a categorização das entrevistas - e assim - foi desenvolvido a categoria do corpo-abstinente e o distanciamento da integralidade ofertado na assistência em saúde a estes sujeitos.

O projeto de pesquisa foi aprovado pelo Comitê de Ética e Pesquisa (CEP) do Hospital São José de Doenças Infecciosas, sob o número 3.492.692. Ressalta-se, assim, que a pesquisa respeitou os princípios da Bioética descritos na Resolução 466/12 do Conselho Nacional de Saúde. Os participantes assinaram o Termo de Consentimento Livre e Esclarecido (TCLE). 


\section{Resultados e Discussão}

\section{Representações do corpo-abstinente na alta a pedido e fragmentação da assistência: distanciamentos da integralidade do cuidado às pessoas que usam drogas, vivem em situação de rua e com HIV/Aids}

De modo geral, através das narrativas dos trabalhadores de saúde, foi possível perceber o que o corpo de um usuário de drogas, que vive com HIV/Aids e em situação de rua significa e representa ao serviço de atenção à saúde. Falas e expressões carregadas de estigmas e preconceitos permeiam as práticas clínicas, bem como uma multiplicidade de opiniões, posicionamentos e (des)interesses no tocante cuidado em saúde. Aqui encontraremos uma diversidade de realidades. Onde o corpo-abstinente resiste e assim, se reinventa em cada alta a pedido, a cada nova internação; e a fragmentação do cuidado a estes sujeitos ofertados por trabalhadores de saúde.

David Lapoujade, segundo Lins e Gadelha (2002) suscita que o corpo não aguenta mais. Isto é um fato - não é uma cogitação, nem tampouco uma tese. Em consonância com David Le Breton (2011), reitera que as expressões corporais através da arte e da visão sociológica o sujeito reproduz posturas elementares: deitado, sentado, esticado, inclinado, imobilizado, os dançarinos que escorregam, os corpos que caem ou se torcem, que se mutilam, que gemem e gritam; os corpos acelerados, desacelerados, adormecidos. Eles se rastejam. Eles recaem.

Quando falamos de um corpo abstinente, de um corpo que vive com HIV/Aids, que vive em situação de rua e usuário de drogas, estamos falando de um corpo que, segundo a teoria de Carreteiro (2005), é um corpo excesso, identificado como aquele corpo que opta e escolhe por viver o excesso, por transbordar de forma consciente ou subconsciente aquilo que lhe convém ou não, sendo visto, portanto, por muitos trabalhadores de saúde, um corpo objeto; um corpo problemático, difícil de lidar e que, por vezes, não dão o devido valor ao tratamento.

(...) ele fica irritado, agressivo, nada tá bom, procurando problemas para poder sair. É, é... muito difícil, né. Porque você está tentando aliviar a dor e ao mesmo tempo eles estão proporcionando, é, é... muitas vezes eles ficam aqui porque a família obriga (...) mas ele não quer mais nem se internar, ali do corredor mesmo ele volta, eles preferem ficar na rua do que ficar internado. Os de rua mesmo não querem ficar aqui, querem ficar na rua. O tratamento deles é muito difícil, muito difícil. (...) porque geralmente eles são muito rebeldes, agressivos, né. Agride os profissionais, os outros acompanhantes, os vizinhos, os pacientes, na maioria das vezes eles são agressivos. Eles querem é abandonar. Para eles não tem valor nenhum o tratamento. isso fora as fugas (...) (Raffflesia Arnoldii)

Mediante as falas da Raffflesia Arnoldii é possível perceber como este corpo é visto, compreendido e tratado. David Lapoujade (2002) problematiza a potência que o corpo tem que, mesmo no esmagamento, este corpo (re)existe, resiste. Uma potência que é liberada mediante há um ato; no caso, a opção por se reinventar a cada internação, quando a imunidade baixa e as infecções oportunistas se apropriam; quando o usuário é obrigado a passar por um processo de abstinência. O corpo resiste quando ele é visto por trabalhadores de saúde difíceis de lidar, porque, de fato, ele não aguenta mais. Ele resiste mesmo quando ver a alta a pedido como solução para resolver seu quadro de fissura pela droga porque encontra-se em abstinência.

Foucault e Nietzsche (1994) problematizam sobre o corpo não poder mais suportar certas exposições. Assim, reencontramos aqui a resistência que o corpo manifesta contra os mecanismos de adestramento do sistema, ou seja, a alta a pedido, uma vez que a política de abstinência é imposta para que o usuário permaneça na unidade de saúde e assim ser tratado. É o que podemos observar na fala da Jade Vine:

(...) Aí eles vão e assinam à alta e vão embora, depois volta. Paciente que estão aqui sempre. Quando eles estão na abstinência muito grande, eles assinam e vão embora. Porque os pacientes daqui são assim, vão e voltam, vão e voltam... Isso, porque devido a droga eles sempre vão estar aqui nos corredores até chega um dia que morre, né, por que os pacientes daqui é assim... Têm duas aqui que é um retrato da abstinência. Elas ficam agitadas. Elas fica, né... entendeu... (...) (Jade Vine). 
Em contrapartida, Orquídea Azul, reafirma a importância de olhar para este corpo com integralidade e responsabilidade, o que, em conformidade com Souza Neto et al. (2018), Magnabosco et al. (2018), Almeida et al. (2018) e Cruz, Vargens e Ramôa (2011) nos faz pensar que o aperfeiçoamento é necessário no cuidado em saúde, em especial, a este corpo que vive com HIV/Aids, em situação de rua e que faz uso abusivo de drogas. Esse cuidado deve ser, portando, um cuidado integral e resolutivo, visando, sobretudo, a continuidade deste cuidado. Vejamos o que Orquídea Azul diz sobre o que é observado mediante as suas práticas assistenciais e o que ela enxerga neste corpo:

(...) as vezes gera até um estigma, as vezes a gente nem se dá conta da quantidade de pessoas que abandonam por conta de viver nessas condições. E no internamento é a questão da pessoa que quer sair de alta, tá em crise de abstinência, né, porque tá sem o uso da substância, tá em abstinência, mas é visto como aquela que não quer se tratar; ele não tem problema, ele não tem uma situação que precise de um atendimento especializado, não, é aquela pessoa que não quer se tratar, e sai de alta a pedido, né (...) se a gente não trabalha na integralidade, né, como é que vai ter o sucesso dessa adesão... Ai essas pessoas vão e voltam, vão e voltam, né (...) (Orquídea Azul).

Partindo desta perspectiva, David Lapoujade (2002) questiona sobre: o que é o corpo que sofre? Associando, portanto, com o corpo abstinente e as impressões observadas mediante as falas dos trabalhadores de saúde, o sofrimento de um usuário de drogas, que vive em situação de rua e que vive com HIV/Aids é percebido quando manifesta a sintomatologia, propriamente dita, da abstinência, como revelam Lotus berthelotii e Franklinia alatamaha:

(...) Eles soam, eles têm sudorese é, eles ficam agitados. É isso aí é, é muito difícil. É, algumas atitudes. E é, como se diz? Alguns sintomas né? Primeiros vem os sintomas, né? Eles começam a suar, tem uns que começa parece uma febre, mas não é febre, aí vem à irritação, né? Vem a inquietação. Aí é muitas coisas junta (...) (Lotus Berthelotii).

(...) Hipoglicemia, é... taquicardia, é... sudorese, muita sudorese. Desorientação; vai de acordo com o paciente também (...) (Franklinia alatamaha).

Sendo assim, identificamos por meio das falas dos trabalhadores de saúde que muitos usuários que estão nesta condição optam pela alta a pedido. E assim, por estarem em abstinência, não conseguem concluir o tratamento. Após voltarem para a rua, depois de um determinado tempo, retornam ao serviço com a sua condição clínica mais debilitada e com o processo de recuperação bem mais retardado. Esta condição no serviço acaba se tornando um ciclo um tanto quanto curioso, uma vez que partimos de uma perspectiva que o sistema impõe para este usuário, a abstinência.

(...) não é só a doença do corpo, é a doença da alma, né, que eles têm (...) (Jade Vine).

(...) Eu entendo com uma fraqueza, qualquer tipo de visto para mim, eu pessoalmente, para mim, eu entendo com uma fraqueza (...) (Lotus Berthelotii).

Lins e Gadelha (2002) trazem que Nietzsche e Deleuze afirmam que a primazia de pathos, que vem do grego que deu origem a palavra patologia, são turbulência do contato com estrangeiro (intensidade e paixão) e não os de afinidade ou boa vontade (representação).

Transpondo a ideia de corpo patológico no âmbito da saúde, Carreteiro (2005) afirma que este corpo é visto pelos trabalhadores de saúde como um corpo excesso. David Lapoujade (2002) em Nietzsche reitera ainda que: o corpo “originariamente o sofrimento da impressão e o reconhecimento de uma impressão estrangeira".

Vale, portanto, retornarmos sempre a essa questão: desde sempre e para sempre que não aguentamos mais. Desde sempre e para sempre que resistimos. É isto que este corpo-abstinente, que por sua vez é usuário de drogas, que vive com HIV/Aids e em situação de rua nos fala dentro de um sistema de saúde. A sua integralidade e resistência não são enxergadas. Este corpo é visto através da sintomatologia da fissura pela droga. Um corpo taxado como problemático e não digno de um cuidado tanto singular, quanto em suas pluralidades de sentidos. 


\section{Considerações Finais}

À guisa-se de conclusão, as subjetividades de um corpo-abstinente que vive com HIV/Aids, em situação de rua e que faz uso abusivo de drogas é enxergado dentro do sistema de saúde como problemático, agressivo, caprichoso e que não quer tratamento.

É válido problematizarmos que a oferta de um cuidado fragmentado resulta numa assistência rudimentar, o que leva o sujeito a ir embora de alta a pedido, voltar para a rua e, por conseguinte, retornando ao serviço com sua condição clínica e sobretudo, humana, ainda mais debilitada. Foi possível perceber que isso se tornou um ciclo recorrente na realidade do serviço. O fato de o trabalhador de saúde não conseguir ir além da sintomatologia de um corpo-abstinente faz com que a integralidade do cuidado não seja atendida.

Faz-se necessário, ainda, questionar: como este corpo-abstinente enxerga o cuidado na atenção terciária em saúde? Tendo em vista a necessidade de buscar por uma reconstrução dessa assistência, pois na realidade pesquisada ela demonstrou e se reafirmou fragmentada e incompleta, o que resulta numa gama de problemas clinico, socioeconômico e humano. Compreender que a assistência ao usuário que vive com HIV/Aids, em situação de rua e que faz uso abusivo de drogas é primordial para o alicerce de uma prática assistencial, coerente e eficaz.

\section{Referências}

Almeida, R. B. F., Santos, N. T. V., Brito, A. M., Brito e Silva K. S. \& Nappo, S. A. (2018). Treatment for dependency from the perspective of people who use crack. Interface, 22(66), 745-56. 10.1590/1807-57622016.0940

Cruz, M. S., Vargens, R. W. \& Ramôa, M. L. (2011). Crack, uma abordagem multidisciplinar. In Prevenção ao uso indevido de drogas: Capacitação para Conselheiros Lideranças Comunitárias (pp. 194-214). SENAD.

Caprara, A. \& Veras, S. (2005). Hermenêutica e narrativa: a experiência de mães de crianças com epidermólise bolhosa congênita. Interface - Comunicação, Saúde, Educação, 9(16), 131-146.https://doi.org/10.1590/S1414-32832005000100011

Carreteiro, T. C. (2005). Corpo e contemporaneidade. Psicol. em Rev. Belo Horizonte, 11(17), 62-76. http://periodicos.pucminas.br/index.php/psicologiaemrevista/article/view/220

Castel, R. (2010). As metamorfoses da questão social: uma crônica do salário. (9a ed.). Vozes.

Epele, M. (2012). Sobre o cuidado de outros em contextos de pobreza, uso de drogas e marginalização. MANA, 18(2), 247-268. https://doi.org/10.1590/S0104-93132012000200001

Foucault, M. (1994). Nietzsche, la généalogie, l'histoire, en Homanage a Jean Hyppolite. reeel. en Dits et écrits, Gallimarel, Paris.

Góis, J. S. (2017). Entre "noieiros", “drogueiros" e “anormais”: experiências de vida das pessoas que vivem com HIV/Aids e fazem uso de crack. Dissertação de Mestrado, Programa de Pós-Graduação em Saúde Coletiva, Centro de Ciências da Saúde, Universidade Estadual do Ceará. Fortaleza, Brasil. http://www.uece.br/ppsac/wp-content/uploads/sites/37/2018/08/JHENNIFER-DE-SOUZA-G\%C3\%93IS.pdf

Ivo, A. M. S. (2012). Representações de pessoas com HIV/AIDS sobre o corpo: a construção da corporeidade. Rev. Reme. 18(4). http://www.dx.doi.org/10.5935/1415-2762.20140065

Le Breton, D. (2011). Antropologia do corpo e modernidade. Vozes.

Lins, D. \& Gadelha, S. (Orgs). (2002). Nietzsche e Deleuze: o que pode o corpo. Relume Dumará.

Machado, A. R., Modena, C. M. \& Luz, Z. M. P. (2020). O que pessoas que usam drogas buscam em serviços de saúde? Compreensões para além da abstinência. Interface (24): e190090 https://doi.org/10.1590/ Interface.190090

Magnabosco, G. T. et al. (2018). Assistência ao HIV/Aids: análise da integração de ações e serviços de saúde. Esc. Anna Nery Rev. Enferm., 22 (4):e20180015. DOI:http://dx.doi.org/10.1590/2177-9465-ean-2018-0015.

Merhy, E. E. \& Feuerwerker, L. C. (2009). Novo olhar sobre as tecnologias de saúde: uma necessidade contemporânea. In Mandarino, A. C. S. \& Gomberg, E. (Orgs.). Leituras de novas tecnologias e saúde. Editora UFS.

Minayo, M. C. S. (Org.), Deslandes, S. F. \& Gomes, R. (2013). Pesquisa Social: teoria, método e criatividade. (33a ed.). Vozes.

Pedrosa, S. M., Reis, M. L., Gontijo, D. T., Teles, S. A. \& Medeiros, M. (2016). The path to crack addiction: perceptions of people under treatment. Rev Bras Enferm, 69(5), 899-906. http://dx.doi.org/10.1590/0034-7167-2016-0045 
Research, Society and Development, v. 11, n. 2, e51711226011, 2022 (CC BY 4.0) | ISSN 2525-3409 | DOI: http://dx.doi.org/10.33448/rsd-v11i2.26011

Resende, C., Borges, H. M. O. C., Passos, E., Moraes, M. \& Ribeiro, R. S. T. (2017). Que lugar para a corporeidade no cenário dos saberes e práticas psis? Fractal, Rev. Psicol., 29(2), 89-95. https://doi.org/10.22409/1984-0292/v29i2/2330

Ricoeur, P. (1989). Do texto à acção. RÉS.

Schwengber, M. S. V. (2005). Corpo-Sujeito. In Gonzáles, F. J., Fensterseifer, P. E. In Dicionário Crítico de Educação Física (pp. 104-106). Unijuí.

Souza Neto, V. L. et al. (2018). Proposta de plano de cuidados de enfermagem para pessoas internadas com Aids. Rev. Esc. Enferm USP, 51 : e03204. http://dx.doi.org/10.1590/S1980-220X2016027203204 